\title{
Pediatric Rheumatology
}

\author{
Reem Abdwani
}

\subsection{Introduction}

Musculoskeletal (MSK) complaints in children are common. However, not all MSK complaints are due to rheumatic diseases. Etiologies range from benign conditions to serious conditions requiring prompt attention. Therefore, a complete history and physical examination, in addition to essential investigations and imaging, is essential to distinguish rheumatic conditions from other diseases (Fig. 24.1). Most of the differential diagnoses have been covered in other chapters; however, besides trauma and infectious causes including septic arthritis and reactive arthritis, some common causes of non-rheumatic joint pain in children include the following:

Toxic synovitis of the hips is a common selflimited form of reactive arthritis usually occurs after an upper respiratory tract infection commonly affecting boys younger than 8 years. The child presents with painless limp or complains of pain in the groin, anterior thigh, or knee (referred pain). Unlike patients with septic arthritis, the child appears well, while the affected limb is held in a position of external rotation and flexion. Investigations are normal or show mild increases in inflammatory markers. Management is supportive with rest and analgesia.

R. Abdwani ( $ه)$

Department of Pediatrics, Sultan Qaboos University, Seeb, Oman

e-mail: rmabdwani@squ.edu.om
Growing pain is benign short-lived vague pain limited to calf, thigh, and shin commonly affecting children between the ages of 3 to 10 years. Pain is severe in intensity, often occurs late in the day, or awakens the child at night. The child is otherwise well and asymptomatic during the day, having no functional limitations. The pain is intermittent in nature, with symptom-free intervals lasting days to months. There is often a family history of growing pains. Importantly, the physical examination, laboratory data, and radiological investigations are normal. Management consists of reassurance and supportive analgesia.

Childhood malignancies, such as leukemia, lymphoma, and neuroblastoma, may present with daytime and nighttime joint pain. Clinical characteristics include severe pain that is out of proportion to clinical findings, lack of morning stiffness, and the ability to localize the pain to the bone on palpation. Patient may have constitutional symptoms including fever, weight loss, and night sweats. Similarly, the presence of thrombocytopenia and high LDH may indicate the presence of malignancy.

Slipped capital femoral epiphysis (SCFE) is a condition in which the femoral head is displaced from femoral neck. It commonly affects overweight boys between the ages of 10 and 14 years or children with endocrine problems such as hypothyroidism or growth hormone deficiency. The complaint of hip pain may be acute or insidious and can frequently present with knee 


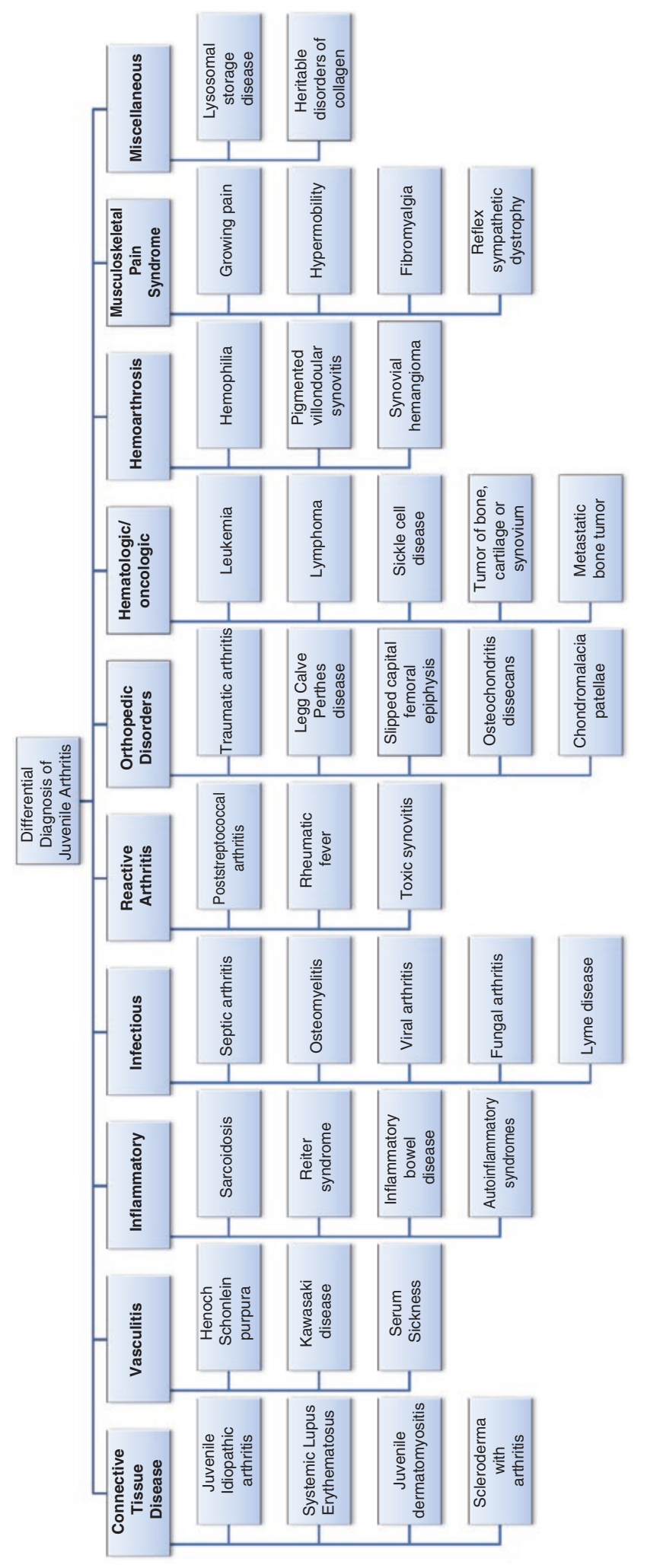

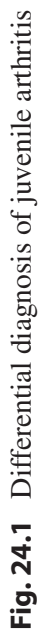


pain. Examination reveals a flexed and externally rotated hip with painful and limited passive internal rotation. Diagnosis is radiological and patients should be placed on non-weight-bearing crutches until an urgent orthopedic consultation for a surgical intervention is made.

Legg Calve Perthes disease is self-limiting avascular necrosis of the femoral capital epiphysis commonly affecting boys from 4 to 10 years. Children present with painful limp and limited range of motion of the hip joint. Initial radiographs may be normal; therefore, MRI is more sensitive in detecting early disease. Patients should be kept non-weight-bearing until an urgent orthopedic referral. Treatment is aimed at maintaining the femoral head within the acetabulum, which can be achieved conservatively with abduction splints or casts or surgically with an osteotomy of the proximal femur.

\subsection{Learning Objectives}

By the end of this chapter, you should be able to:

- List common causes of non-rheumatic joint pain in children.

- Recognize some of the similarities and differences between childhood and adult onset rheumatic diseases.

- Distinguish the characteristic clinical features of juvenile idiopathic arthritis subtypes.

- Explore the classification criteria of pediatric vasculitis with emphasis on the clinical presentation and management of Kawasaki disease.

- Discuss the spectrum of autoinflammatory syndromes.

\subsection{Pediatric Rheumatic Diseases}

Children are not little adults. By acknowledging the similarities and difference between adult and childhood types of rheumatic diseases, it will be easier to identify those features that are characteristic of or specific to children. Many pediatric rheu- matic diseases have different disease phenotypes, outcome measures, investigations, and treatment that are distinct from adult rheumatic diseases. The next sections will highlight the clinical features that are specific to pediatric rheumatic diseases.

\subsection{Childhood Onset SLE}

The diagnosis and treatment of childhood onset SLE (cSLE) is similar in many aspects to adult SLE (aSLE). However, differences in disease demographics, clinical presentation, disease course, and outcome exist between cSLE and aSLE.

Onset of SLE during childhood period occurs in 10-20\% of all SLE cases. There is less female prediction in cSLE as the female to male ratio with pediatric SLE changes from 4:3 with disease onset during the first decade of life to $4: 1$ during the second decade to 9:1 in aSLE [1]. cSLE often presents with more acute and severe disease manifestation at the time of diagnosis with a higher frequency of renal, neurological, and hematological involvement, while cutaneous and musculoskeletal features are more common at disease onset in aSLE [2]. SLE Disease Activity Index (SLEDAI), at diagnosis and over disease course, tends to be much higher in cSLE [3]. Comparative studies support that cSLE is more often treated with high doses of corticosteroids and immunosuppressive medications than aSLE [4]. Despite improved survival rates in SLE patients, there remains substantial morbidity due to disease damage. cSLE is associated with more rapid accrual of damage than is SLE in adults, and it involves mostly ocular, renal, and musculoskeletal damages [4].

\subsection{Juvenile Dermatomyositis}

Adult and juvenile onset dermatomyositis share the hallmark clinical presentation of pathognomic skin rash and muscle weakness described in Chap. 8; however, each has distinct demographics, clinical features, and associated outcomes [5]. 
JDM is rare, with incidence of $2-4$ per million children [6]. The mean age of onset of JDM is 7 years with $25 \%$ of patients presenting younger than 4 years of age [7]. The rash of JDM can be atypical, occurring anywhere in the body, and is more frequently associated with ulcerative change than in adults. Anti-p155/140 autoantibody is the most prevalent myositis specific antibody found in $30 \%$ of patients with JDM and is associated with cutaneous rash with skin ulceration, generalized lipodystrophy, low creatinine kinase levels, and a chronic course of disease [8].

The clinical course in JDM is monophasic (40-60\%), chronic (40-60\%), and polyphasic $(>5 \%)$.

Predictors of chronic course include delay in treatment, higher skin disease activity at baselines, ongoing Gottron's papules and periungual nail fold capillary changes beyond 3 months of treatment [9]. In addition, the presence of subcutaneous edema on MRI at diagnosis and extensive myopathic and severe arteropathic changes on the initial muscle biopsy are predictors of a chronic illness course [9]. Approximately $20-47 \%$ of patients with JDM develop calcinosis at presentation or after many years of illness [10]. JDM has not been clearly associated with the development of malignancy which is a significant cause of mortality in adults with DM.

Treatment of JDM consists of combination of corticosteroids (2 mg/kg) with slow taper and methotrexate $15 \mathrm{mg} / \mathrm{m}^{2} \mathrm{~s} / \mathrm{c}$. Other treatment modalities include cyclophosphamide for interstitial lung disease or vasculitis. IVIG, cyclosporine, mycophenolate mofetil, and rituximab are used in refractory cases.

\subsection{Juvenile Idiopathic Arthritis}

Juvenile idiopathic arthritis (JIA) is comprised of a heterogeneous group of several disease subtypes that are characterized by the onset of arthritis prior to the age of 16 years with symptoms that persist for more than 6 weeks after exclusion of other causes of juvenile arthritis Fig. 24.1. Arthritis is diagnosed in the presence of joint effusion or two or more of the following: limited range of movement, joint line tenderness, or painful range of movement and warmth. The current classification system by the International League of Associations for Rheumatology (ILAR) recognizes seven distinct subtypes of JIA, based on their presentation within the first 6 months [11]. The categories of JIA and their diagnostic criteria are defined in Fig. 24.2. There is evident heterogeneity with respect to demographic, genetic, and clinical features among the JIA subtypes, translating into heterogeneity in the responses to treatment.

Oligoarticular JIA is the most common subtype with relative frequency of $30-60 \%$ in Caucasian population with peak age at 1-3 years [11]. It is divided into two further subsets: persistent, if arthritis remains confined to four or fewer joints during the whole disease course, and extended, if arthritis spreads to more than four joints after the initial 6 months of illness. The arthritis affects medium to large size joints with the knee being most common joint affected followed by ankle and wrist. Both wrist and ankle arthritis in addition to elevated inflammatory markers (ESR) at disease onset have been recognized as predictors of an extended course [12]. The classic disease phenotype includes asymmetric arthritis, early disease onset, female predilection, high frequency of positive ANA, and high risk of uveitis [13]. Positive ANA represents a high-risk factor for development of chronic uveitis which occurs in $20-30 \%$ of oligoarticular JIA [14]. Chronic uveitis can be asymptomatic until the point of visual loss, making it crucial to undergo regular ophthalmologic screening (Fig. 24.3) [15].

Polyarticular JIA, subdivided into rheumatoid factor positive and rheumatoid factor negative, accounts for $10-30 \%$ of JIA cases occurring most commonly in young girls with an early peak between ages 1-4 years and a later peak of 6-12 years [11]. It is likely that the older group with rheumatoid factor positivity represents disease that is similar to adult rheumatoid arthritis. The arthritis tends to be symmetrical and involves large and small joints [16]. In contrast to oligoarticular JIA, systemic manifestation including low grade fever, anorexia, malaise, and growth failure can be present [16]. Chronic 
International League of Associations for Rheumatology (ILAR) classification of JIA

\begin{tabular}{|c|l|}
\hline Systemic-onset JIA & $\begin{array}{l}\text { Systemic arthritis is diagnosed if there is arthritis in } 1 \text { or more joints with, or } \\
\text { preceded by, fever of at least } 2 \text { weeks' duration. Signs or symptoms must } \\
\text { have been documented daily for at least } 3 \text { days and accompanied by } 1 \text { or } \\
\text { more of the following: evanescent rash, generalised lymphadenopathy, } \\
\text { hepato/splenomegaly, serositis. (Exclusions are A, B, C, and D from the } \\
\text { exclusion list below.) }\end{array}$ \\
\hline $\begin{array}{c}\text { Oligoarthritis is diagnosed if there is arthritis affecting } 1 \text { to } 4 \text { joints during } \\
\text { the first } 6 \text { months. Persistent oligoarthritis affects up to } 4 \text { joints throughout } \\
\text { the course of the disease, and extended oligoarthritis affects more than } 4 \\
\text { joints after the first } 6 \text { months of disease. (Exclusions are A, B, C, D, and E } \\
\text { from the exclusion list below.) }\end{array}$ \\
\hline RF-negative polyarthritis \\
$\begin{array}{l}\text { Polyarthritis (RF-negative) is diagnosed if there is rheumatoid factor (RF)- } \\
\text { negative arthritis affecting } 5 \text { or more joints during the first } 6 \text { months of } \\
\text { disease. (Exclusions are A, B, C, D, and E from the exclusion list below.) }\end{array}$ \\
\hline $\begin{array}{l}\text { Polyarthritis (RF-positive) is diagnosed if there is RF-positive arthritis } \\
\text { affecting } 5 \text { or more joints during the first } 6 \text { months of disease. Two or more } \\
\text { RF tests (taken at least } 3 \text { months apart) are positive during the first } 6 \\
\text { months of disease. (Exclusions are A, B, C, and E from the exclusion list } \\
\text { below.) }\end{array}$ \\
$\begin{array}{l}\text { Psoriatic arthritis is diagnosed if there is arthritis and psoriasis, or arthritis } \\
\text { and at least } 2 \text { of the following: dactylitis, nail pitting, onycholysis, and/or } \\
\text { family history of psoriasis (in a first-degree relative). (Exclusions are B, C, } \\
\text { D, and E from the exclusion list below.) }\end{array}$ \\
\hline $\begin{array}{l}\text { Undifferentiated arthritis is diagnosed if there is arthritis that does not fulfil } \\
\text { criteria in any of the above categories or that fulfils criteria for } 2 \text { or more of } \\
\text { the above categories. }\end{array}$ \\
\hline Psoriatic JIA
\end{tabular}

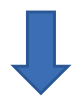

\section{Exclusions}

\begin{tabular}{|c|c|}
\hline A & Psoriasis or history of psoriasis in patients or first-degree relatives. \\
\hline B & Arthritis in HLA B27 positive males beginning after the age of 6 years. \\
\hline C & $\begin{array}{r}\text { Ankylosing spondylitis, enthesitis-related arthritis, sacroiliitis with inflammatory bowel } \\
\text { disease, Reiter's syndrome, acute anterior uveitis, or history ofoneof these disorders in } \\
\text { first-degree relatives. }\end{array}$ \\
\hline D & Presence of IgM rheumatoid factor on at least 2 occasions at least 3 months apart. \\
\hline E & Presence of systemic JIA in patients. \\
\hline
\end{tabular}

Fig. 24.2 International League of Associations for Rheumatology (ILAR) classification of JIA

asymptomatic uveitis develops less frequently and is more common in RF negative polyarticular JIA [11]. Children with RF positive polyarthritis can develop similar complication to adult disease including rheumatoid nodules, Felty syndrome, rheumatoid vasculitis, and pulmonary disease in rare cases [17].

Systemic onset JIA accounts for $10 \%$ of cases of JIA with a broad peak of onset between 1 and 5 years, and it also occurs in adolescence and adulthood [11]. Children of both sexes are equally affected. [18] The systemic symptoms of fever, fatigue, and anemia may overshadow or proceed the arthritis by 6 weeks to 6 months. The arthritis is typically symmetrical and polyarticular and can be extensive and resistant to treatment. The systemic manifestation include fever spikes $>38.5^{\circ} \mathrm{C}$ occurring once or twice daily, which return to baseline or below temperatures. This inflammation is accompanied by a salmon colored evanes- 


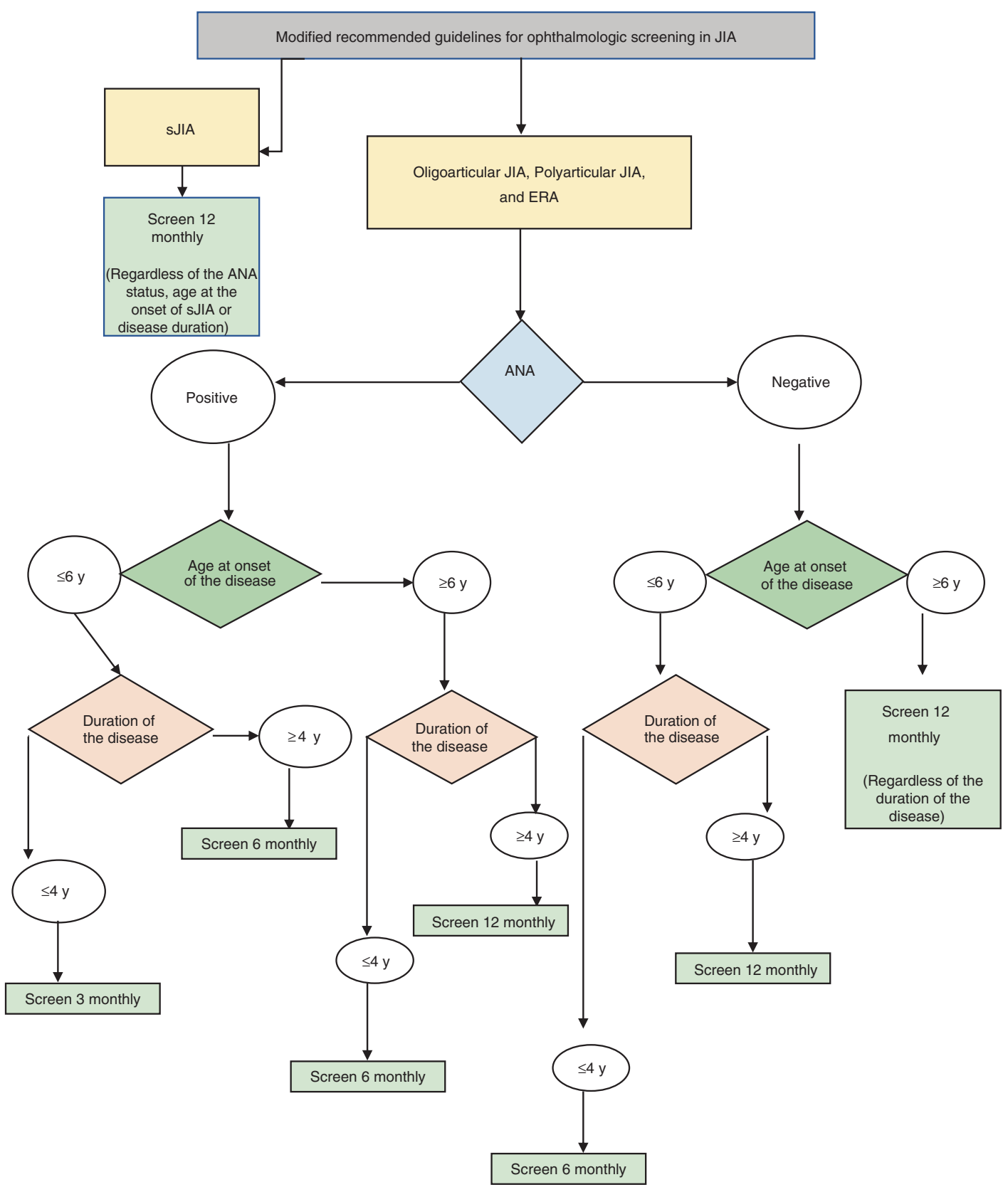

Fig. 24.3 Modified recommended guidelines for ophthalmologic screening in JIA

cent macular rash accompanying fever spikes. Extra-articular manifestation include serositis, hepatosplenomegaly, and lymphadenopathy. An infectious workup and a bone marrow aspirate are strongly considered before starting treatment. Systemic JIA is associated with macrophage activation syndrome (MAS), a potentially life-threatening complication which can manifest as a change in the fever pattern from intermittent to continuous and improvement in arthritis [19]. A recent classification criteria for MAS has been proposed [20] (Fig. 24.4).

Psoriatic JIA (PsA) affects 5\% of patients with JIA and has a bimodal age of distribution in preschool years and in late childhood [11]. Psoriasis often begins after the onset of arthritis 


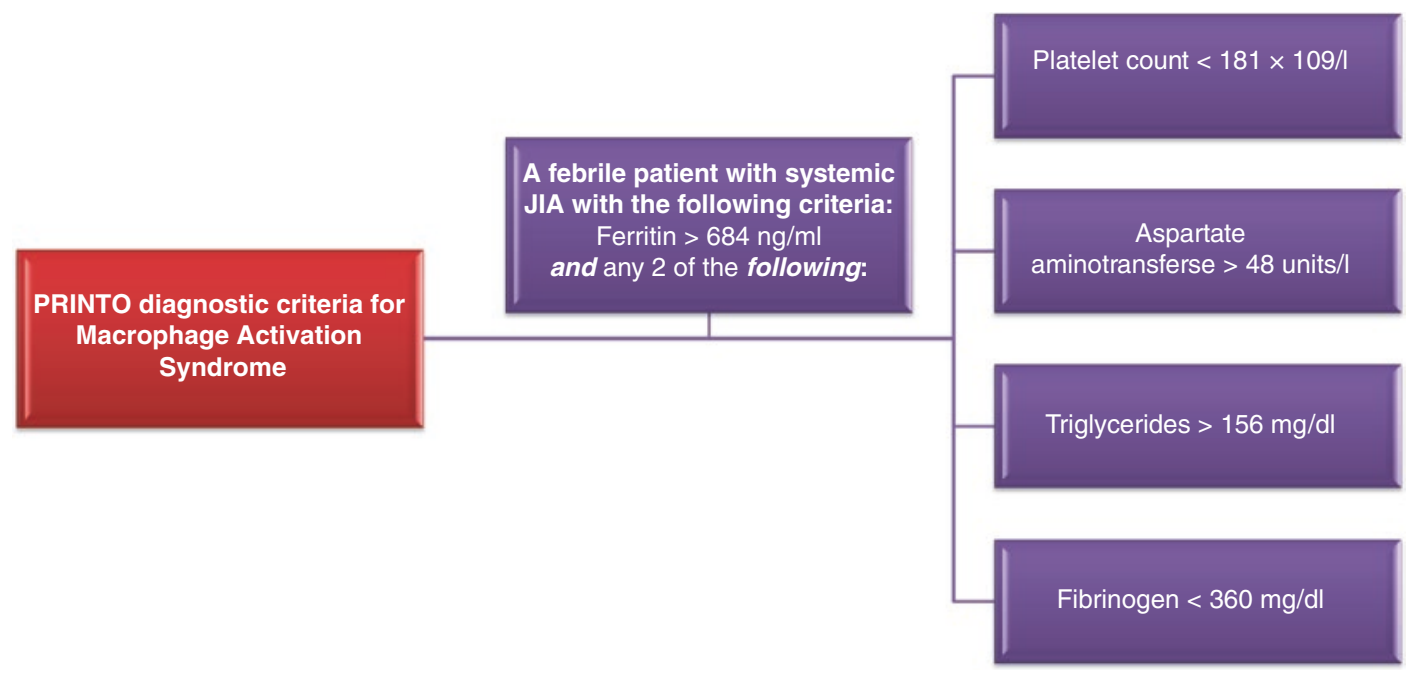

Fig. 24.4 New Classification Criteria for Diagnosis of Macrophage Activation Syndrome

in children and may not be evident [21]. The pattern of joint inflammation is clinically diverse $[22,23]$. Disease at younger age of onset tends to have asymmetric involvement of large and small joints of hand and feet, which differentiates it from oligoarticular JIA [14]. Dactylitis, a clinical hallmark of the disease is also a common manifestation of younger children. Children with older age of onset, who are often HLA B27 positive, tend to develop enthesitis, spinal, and sacroiliac disease [22, 23]. Asymptomatic chronic anterior uveitis occurs in $15-20 \%$ of children with PsA and is associated with the presence of ANA [ 25]. Acute symptomatic anterior uveitis observed in adult patients, is rare in children [25].

Enthesitis-related arthritis (ERA) affects $<5 \%$ of patients with JIA, characterized by the presence of arthritis and enthesitis, typically occurs in boys older than 6 years of age with positive HLA B27 [11]. In contrast to adult ankylosing spondylitis at presentation, axial involvement is not common, while sacroiliitis can be silent [26]. However, axial disease with symptomatic sacroiliitis becomes common within 5 years of diagnosis [27, 28]. Peripheral arthritis of the lower limbs and predominantly the hips is commonly seen [29]. The hallmark of ERA is enthesitis, with resultant pain and swelling at entheseal sites. Other distinguishing manifestation is tarsitis. Symptomatic anterior uveitis may develop in children with ERA, and this usually presents with significant eye pain and redness, which may be unilateral [20]. Although cardiopulmonary involvement is uncommon, aortic insufficiency has been reported.

Undifferentiated arthritis does not represent a distinct subset but includes patients who do not meet the criteria for any category or who meet the criteria for more than one subtype of JIA [30].

Laboratory and Imaging Studies: Most children with JIA have no laboratory abnormalities. Preliminary investigations should be aimed at excluding differential diagnosis (Fig. 24.5). Children with systemic JIA and polyarticular JIA commonly show evidence of inflammation with elevated inflammatory markers and anemia of chronic disease. A complete blood count and peripheral should be performed to exclude leukemia which can present as low WBC and platelet count. ANA should be performed to identify patients at higher risk for developing uveitis, while RF should be performed in polyarticular JIA to identify patients with worse prognosis.

Plain radiographs have limited ability to identify early erosive changes and have poor sensitivity to identify active synovitis. Ultrasound is well suited to assess synovitis, capture erosions, and guide local injections. MRI is able to identify early changes and most sensitive indicator of joint inflammation.

Treatment: The main stay of treatment of JIA aims at controlling inflammation, maintaining 


\section{Preliminary investigation to be considered for
evaluation of Juvenile Idiopathic Arthritis}

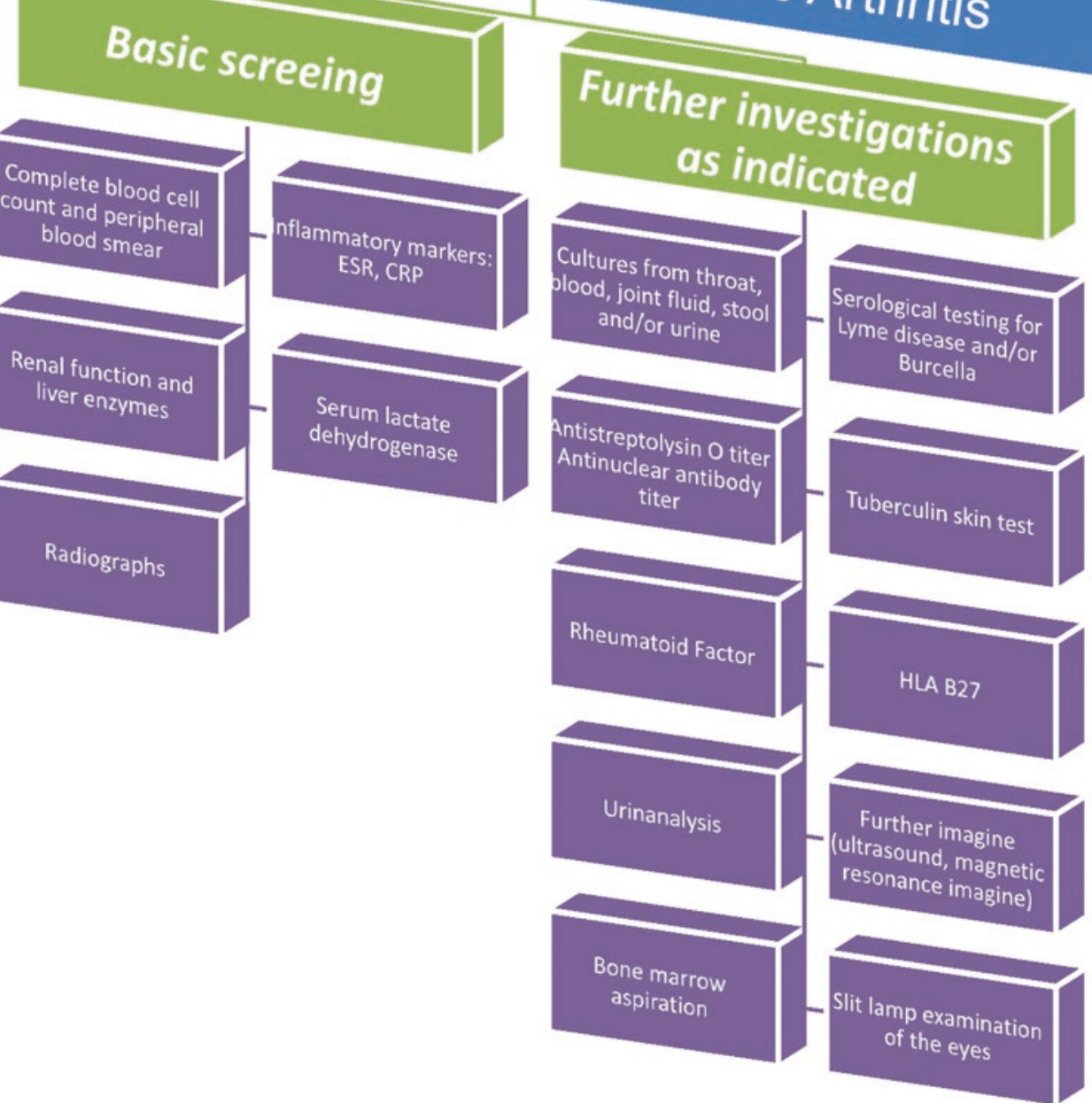

Fig. 24.5 Preliminary investigation to be considered for evaluation of Juvenile Idiopathic Arthritis

function, and preventing joint damage and blindness. This can be achieved through a multidisciplinary team comprising a pediatric rheumatologist, ophthalmologist, orthopedic surgeon, specialist nurse, physical therapist, occupational therapist, and psychologist. ACR treatment recommendations for JIA categories are outlined (Figs. 24.6 and 24.7).

First-line therapy in JIA consists of nonsteroidal anti-inflammatory drugs (NSAIDs). Only a few NSAIDs are approved for use in children: the most common are naproxen (15-20 mg/kg), ibuprofen (30-50 $\mathrm{mg} / \mathrm{kg})$, and indomethacin (1-4 mg/kg). There is limited data on the safety and efficacy of Cox 2 inhibitors [31]. Intraarticular corticosteroids (IAC) may also be used as first line in the treatment of Oligoarticular JIA [32]. Triamcinolone hexacetonide (TH) is the drug of choice for IAC. Due to its lower solubility, it has longer lasting duration of action than other 


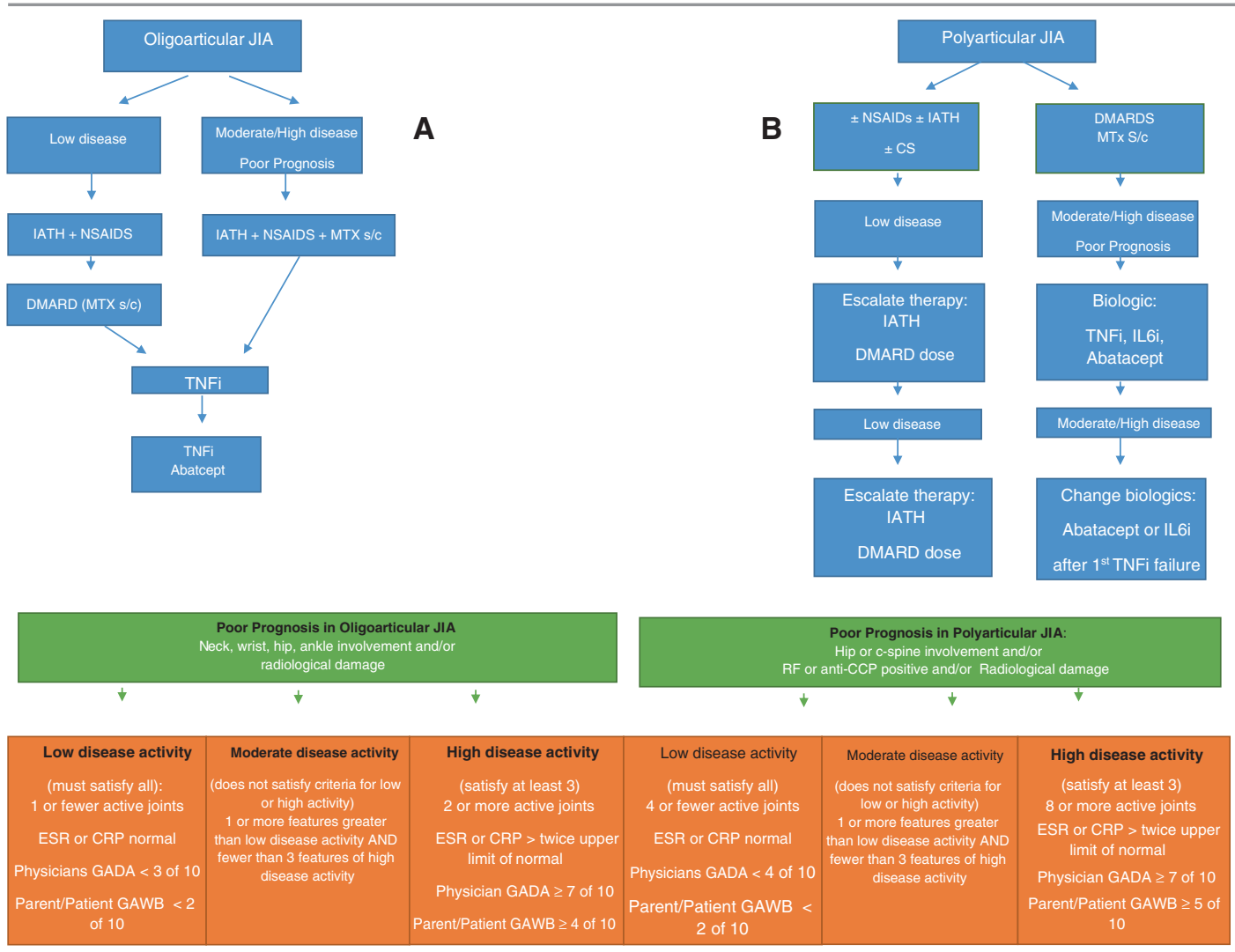

Fig. 24.6 Adopted from 2011 and 2019 American College of Rheumatology Recommendations for Treatment of Oligoarticular JIA (A) and Polyarticular JIA (B). CRP: C reactive protein; ESR: erytherocyte sedimen- tation rate; GADA: global assessement of overall disease activity; GAWB: global assessement of overall wellbeing; IATH: intra-articular trimcinolone hexacetonide

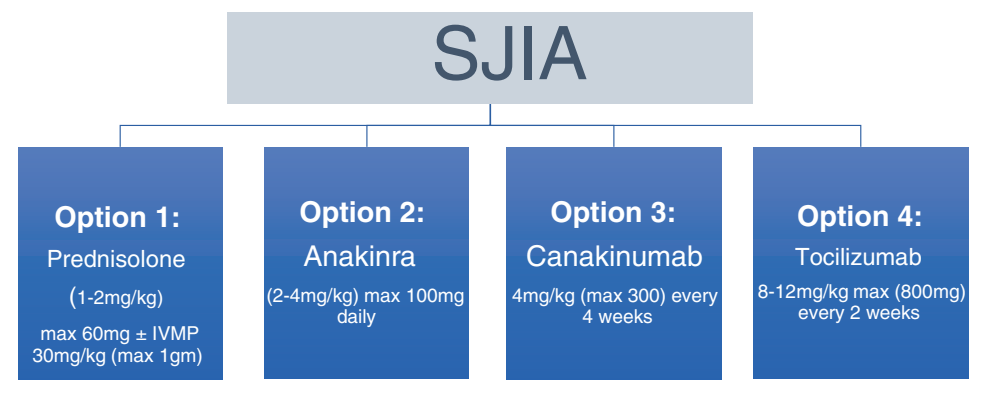

Fig. 24.7 Management of systemic juvenile idiopathic arthritis 
preparations [33]. The dose of $\mathrm{TH}$ administered is $1 \mathrm{mg} / \mathrm{kg}$ ( $\max 40 \mathrm{mg}$ ) for the knee joint or half of this dose for ankle and wrist [24]. The role of systemic corticosteroids is limited to the extraarticular manifestations of systemic arthritis and as a bridging therapy in severe polyarthritis awaiting the therapeutic effects of second-line agents or biologics.

Second-line therapy includes conventional disease modifying antirheumatic drugs (DMARDs). Methotrexate remains the most widely used at a dose of $10-15 \mathrm{mg} / \mathrm{m} 2$ per week either orally or subcutaneously. There is increased bioavailability of the drug in the subcutaneous route at higher doses, and increased efficacy after switching from oral to subcutaneous administration has been reported [34, 35]. Methotrexate should be continued for at least 6-12 months after achieving disease remission. No difference in the relapse rate was found between patients who were discontinued from methotrexate at 12 months vs. 6 months of disease remission [36]. Experience with leflunomide in JIA is limited but is an alternative option in case of intolerance [37].

Biologic DMARDs are shown to be highly safe and effective in the treatment of JIA as demonstrated in various randomized controlled studies with anti-TNF inhibitors (etanercept, adalimumab, infliximab), anti-CLA4 (abatacept), anti-IL1 (anakinra), and anti-IL-6 (tocilizumab) [38-42]. Stepwise treatment algorithms have been proposed by the ACR for treatment of oligoarticular JIA, polyarticular JIA, and systemic onset JIA. However, there is recent evidence to demonstrate the benefits of early aggressive therapy with both conventional and biologic DMARDs in treatment of JIA such as TREAT, STOP JIA, and BeST for Kids studies [43-45].

\subsection{Childhood Vasculitis}

Childhood vasculitis is often a challenging and complex as the diagnosis can be primary or secondary to infections, drugs, and other rheumatic diseases. If vasculitis is suspected, then the approach to history, physical examination, workup, and classification is similar to the approach used in adult vasculitis.
The EULAR/Pediatric Rheumatology European Society (PReS) consensus criteria for childhood onset vasculitis are listed in (Table 24.1) [46]. Of the primary vasculitides, Henoch Schönlein purpura (HSP) and Kawasaki disease (KD) are the most common, while the other vasculitides are observed rarely in childhood [46]. As other types of vasculitides have been previously described in Chap. 19, this section will focus on KD which is of particular interest to pediatric age group.

\subsection{Kawasaki Disease}

Kawasaki disease is an acute, self-limiting systemic vasculitis predominantly affecting the coronary arteries, causing coronary artery aneurysms (CAA) in 15-25\% of untreated patients [47]. The disease has a diverse distribution worldwide with an ethnic bias toward Asians.

KD predominantly affects children younger than 5 years of age with peak age incidence at 2 years. Patients at extreme end of ages, younger than 3 months, or older than 5 years are affected less often but are at increased risk for CAA formation. Pathogenesis of KD is thought to be due to genetic factors and infectious triggers due to disease characteristics which include winter and spring seasonal variation, community outbreaks, increased risk in siblings, and higher risk in Asians even if they migrate to western countries $[48,49]$.

KD presents in children as unexplained fever for $\geq 5$ days with the additional four out of the five characteristic clinical features described in Fig. 24.8. The diagnosis of incomplete KD can be made in children in presence of two to three of the principal clinical features, commonly occurring in young children. The evaluation algorithm of incomplete KD requires the presence of supportive laboratory evidence and echo cardiac findings (Fig. 24.9) [50]. The supplementary supporting laboratory criteria include three of the following: hypoalbuminemia $<30 \mathrm{mg} / \mathrm{dl}$, anemia for age, elevation of alanine aminotransferase, thrombocytosis after 7 days, leukocytosis $>15,000 / \mathrm{mm}^{3}$, and sterile pyuria $\geq 10 \mathrm{WBC} / \mathrm{HPF}$. Diagnostic challenge 
Table 24.1 EULAR/PRES Consensus Criteria for Childhood Vasculitis

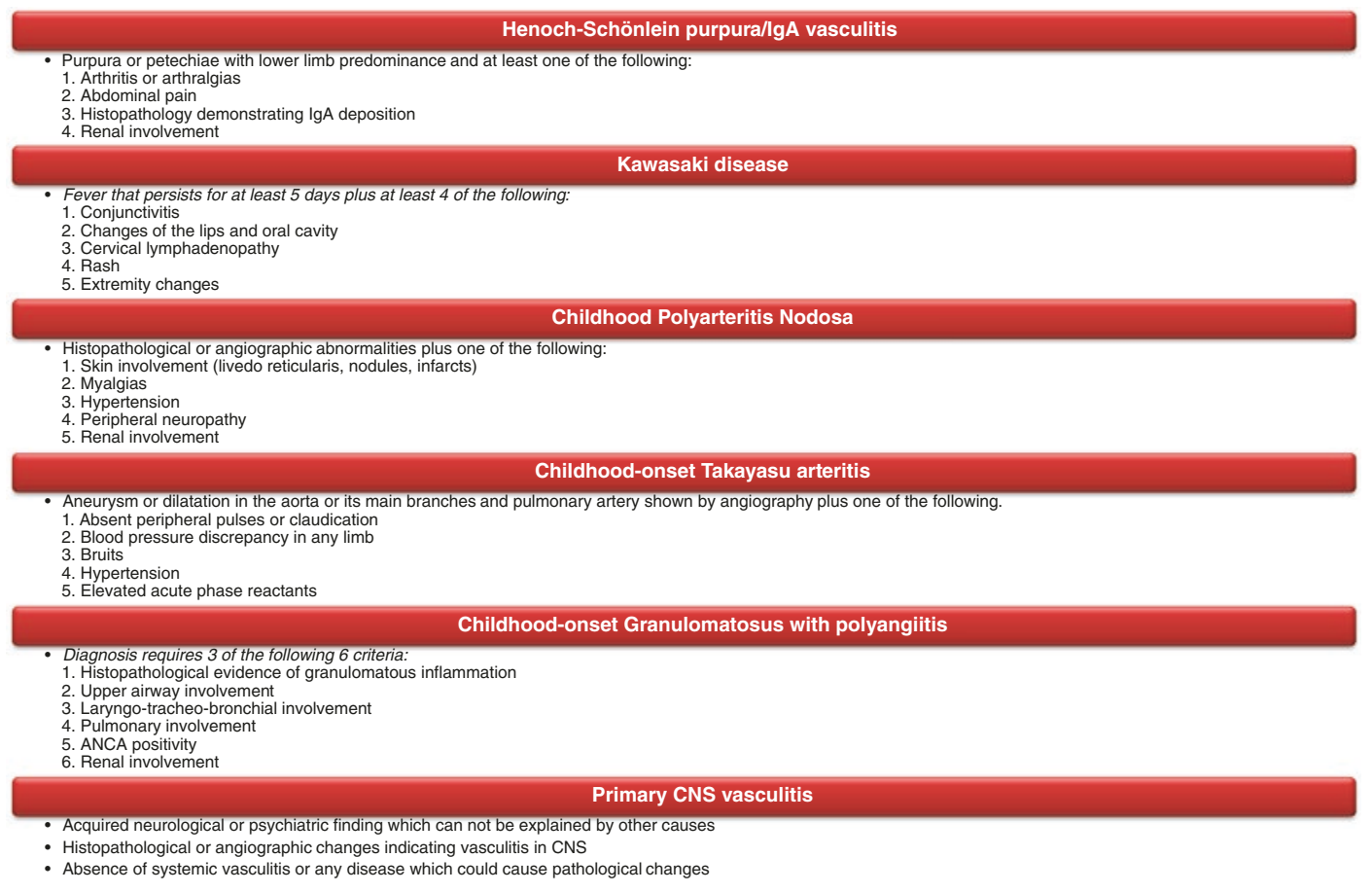

Fig. 24.8 Diagnostic Criteria for Kawasaki Disease

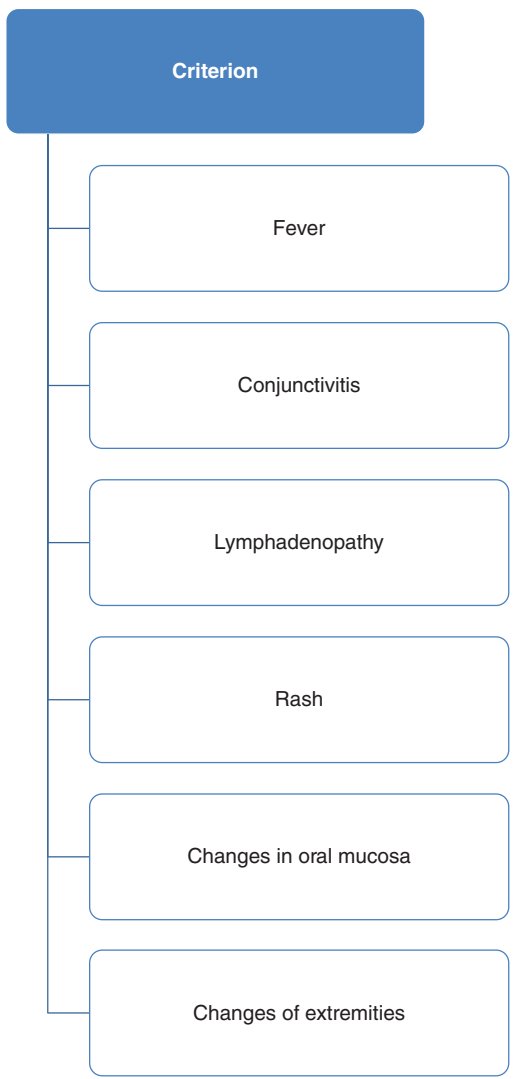

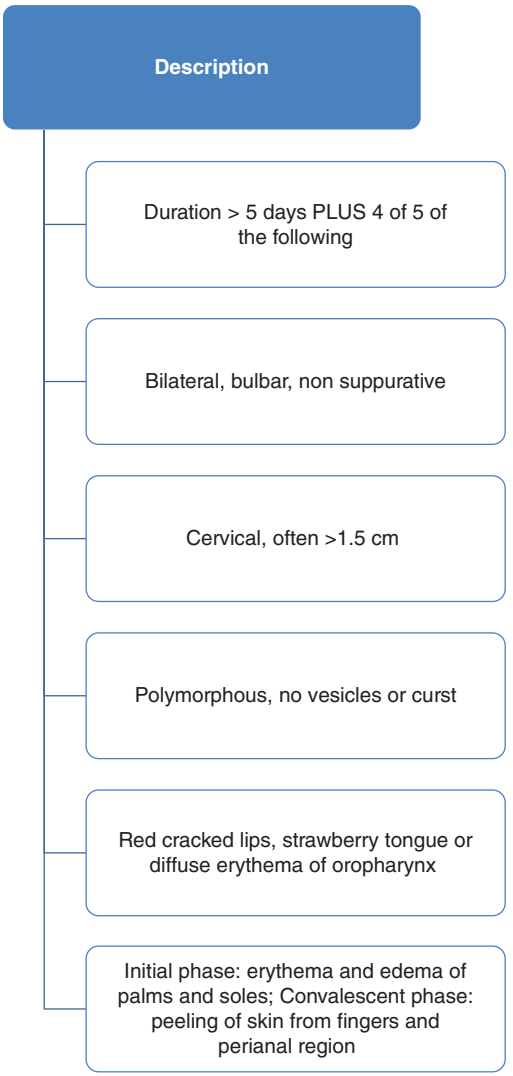




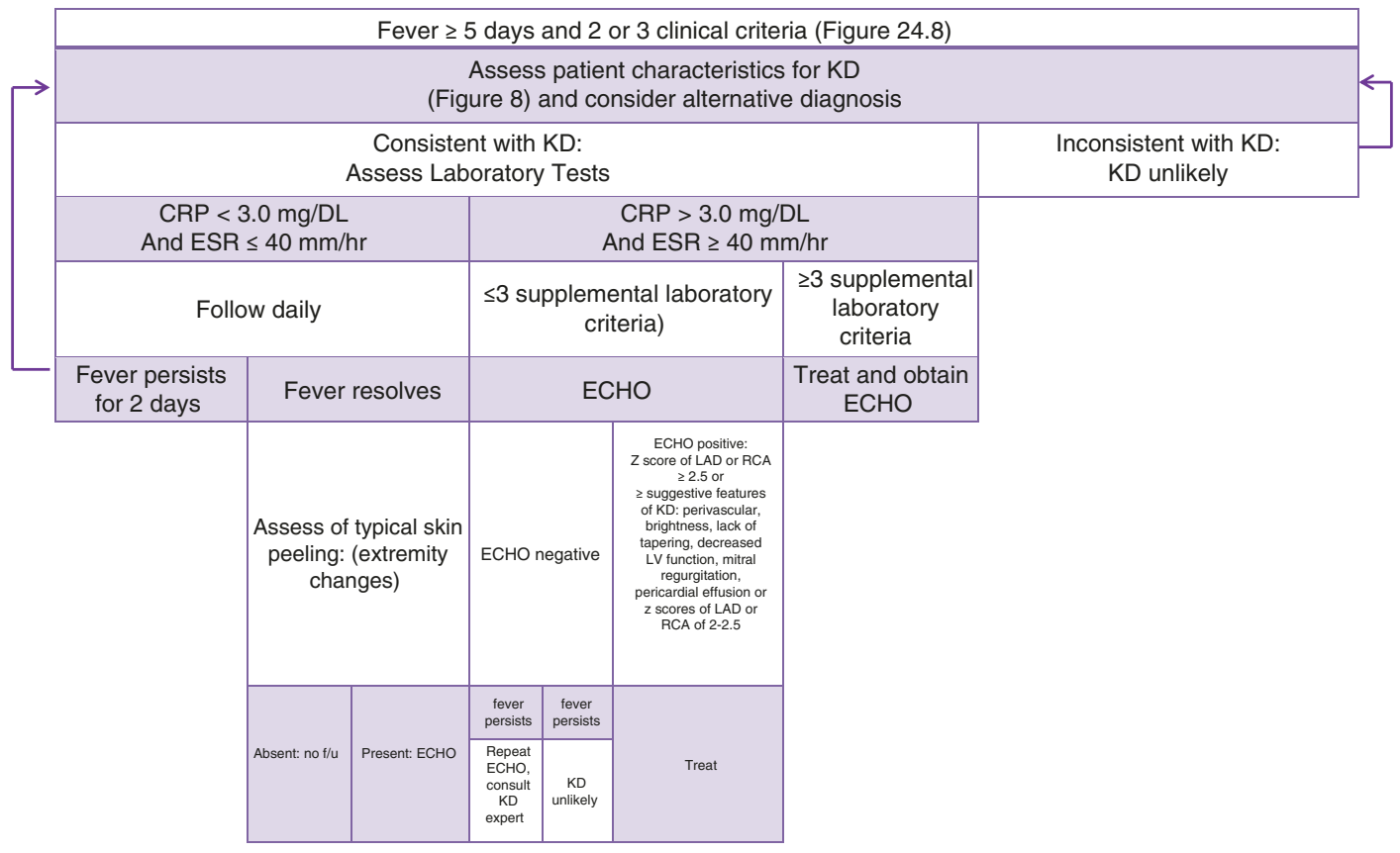

Fig. 24.9 American Heart Association Guidelines for Treatment of KD

Infectious

Adenovirus

Measles

Enterovirus

Epstein-Barr virus

Rubella

Scarlet fever

Rocky Mountain spotted

fever,

Staphylococcal toxic

shock syndrome

Staphylococcal scalded

skin syndrome

\section{Inflammatory}

Systemic Juvenile Idiopathic Arthritis

Polyarteritis nodosa

Behcet disease
Hypersensitivity

Steven Johnson syndrome Drug reaction Mercury hypersensitivity

Fig. 24.10 Differential diagnosis of KD:

often arises given the significant overlap in clinical feature with other pediatric illnesses in (Fig. 24.10). Treatment of $\mathrm{KD}$ as per the American Heart Association (AHA) treatment guidelines includes intravenous immune globulin (IVIG) $2 \mathrm{gm} / \mathrm{kg}$ as single infusion and aspirin (30-50 mg/kg) [50]. Aspirin is then continued until resolution of fever by 48-72 hours before switching to low dose ASA $(5 \mathrm{mg} / \mathrm{kg}$ ) for 6 weeks and until inflammatory parameters normalize. However, approximately $20 \%$ of patients with KD fail to respond to initial treatment with IVIG. [50-52] The RAISE study has demonstrated that treatment of selected highrisk KD patients with IVIG/aspirin was associated with the development of CAA in 23\% [53]. The Kobayashi scoring system has been developed in Japan to predict IVIG resistance and to identify children at highest risk of developing CAA (Table 24.2) [54]. Treatment of severe high-risk KD patients with IVIG/aspirin and corticosteroids in the primary therapy has sig- 
nificantly reduced the development of CA [ 53, 55]. The United Kingdom has developed recent guidelines for the treatment of $\mathrm{KD}$ including patients with high-risk features (Fig. 24.11) suggesting a role for anti-TNF- $\alpha$ if systemic inflammation persists despite IVIG, aspirin, and corticosteroids. [56] Live vaccines should be delayed for at least 3 months following treatment with IVIG, mainly due potential lack of effectiveness and potential detrimental immune activation [7].

Table 24.2 Kobayashi Scoring System for Predicting IVIG Resistance

\begin{tabular}{l}
\hline Kobayashi \\
\hline $\mathrm{Na}<133 \mathrm{mmol} / \mathrm{L}$ ( 2 points $)$ \\
\hline$\leq 4$ days of illness $(2$ points $)$ \\
\hline AST $\geq 100 \mathrm{U} / \mathrm{L}(1$ point $)$ \\
\hline Platelet $\leq 30.0 \times 10^{4} / \mathrm{mm}^{3}(1$ point $)$ \\
\hline $\mathrm{CRP} \geq 10 \mathrm{mg} / \mathrm{dL}(1$ point $)$ \\
\hline Age $\leq 12$ months $(1$ point $)$ \\
\hline$\geq 80 \%$ neutrophils $(2$ points $)$ \\
\hline High Risk: $\geq \mathbf{5}$ points
\end{tabular}

\subsection{Autoinflammatory Syndromes}

Autoinflammatory syndromes (AIS) are a growing cluster of heterogeneous disorders, characterized by recurrent attacks of unprovoked self-limited fever and systemic inflammation involving different sites such as skin, joints, gastrointestinal, or central nervous system. AA amyloidosis is the most serious long-term complication. AIS is secondary to abnormal activation of the innate immune system leading to overproduction of pro-inflammatory cytokines, such as interleukin (IL)-1 $\beta$, and tumor necrosis factor (TNF)- $\alpha$, which leads to pathological delay of inactivation of inflammatory response [57]. The spectrum of monogenic AIS, share overlapping wide range of clinical features as described in (Fig. 24.12) [58].

These syndromes should be suspected in patients, especially young children, typically with recurrent fever and/or with episodic multisystem inflammation, in the absence of infection.

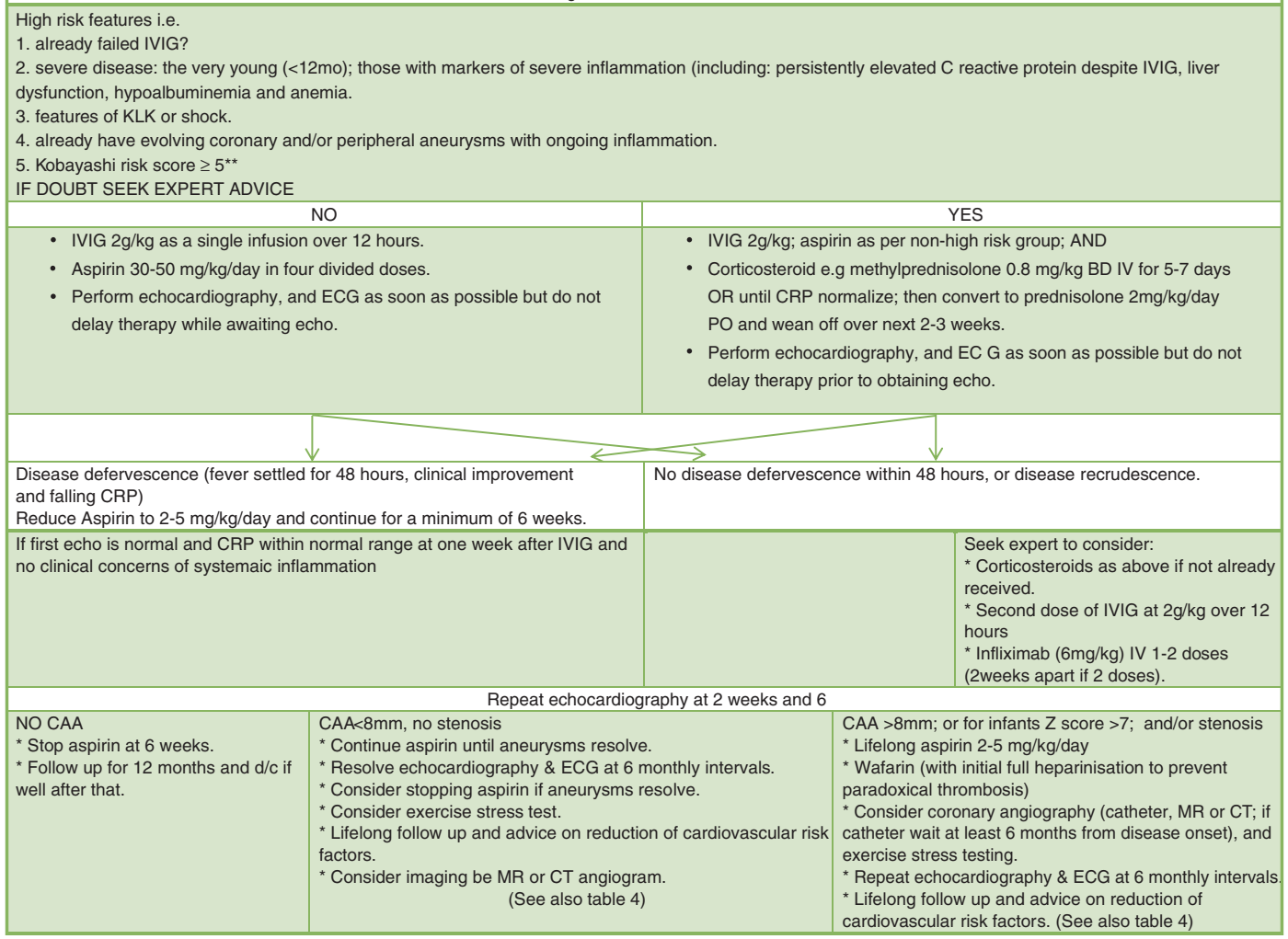

Fig. 24.11 Recommended clinical guideline for the management of Kawasaki disease in the UK 


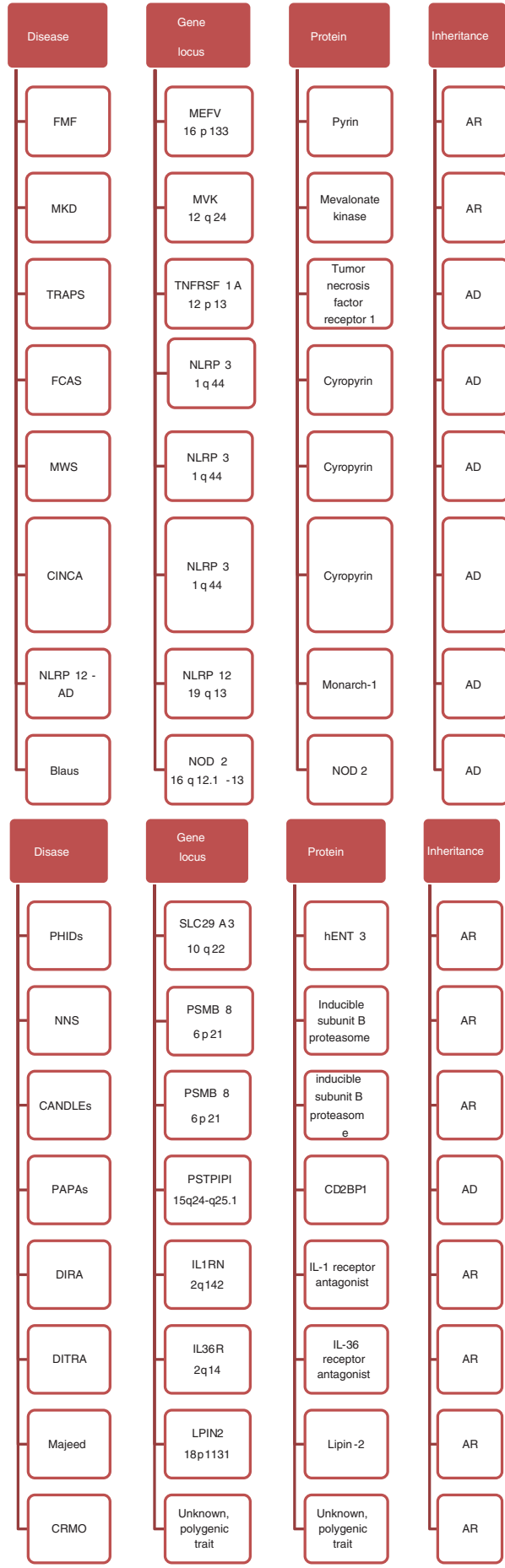

Fig. 24.12 Spectrum of autoinflammatory disease syndromes. AD: autosomal dominant, AR: autosomal recessive, BLAUs: Blau syndrome, CANDLEs: Chronic atypical neutrophilic dermatosis with lipodystrophy and elevated temperature, CINCAs: chronic infantile neurologic cutenous articular syndrome. CRMO chronic recurrent multifocal osteomyelitis, DIRA: deficiency of interleukin-1-receptor antagonist, DITRA: deficiency of IL-36 receptor antagonist, FCAS: familial cold auto-inflammatory syndrome; FMF: familial

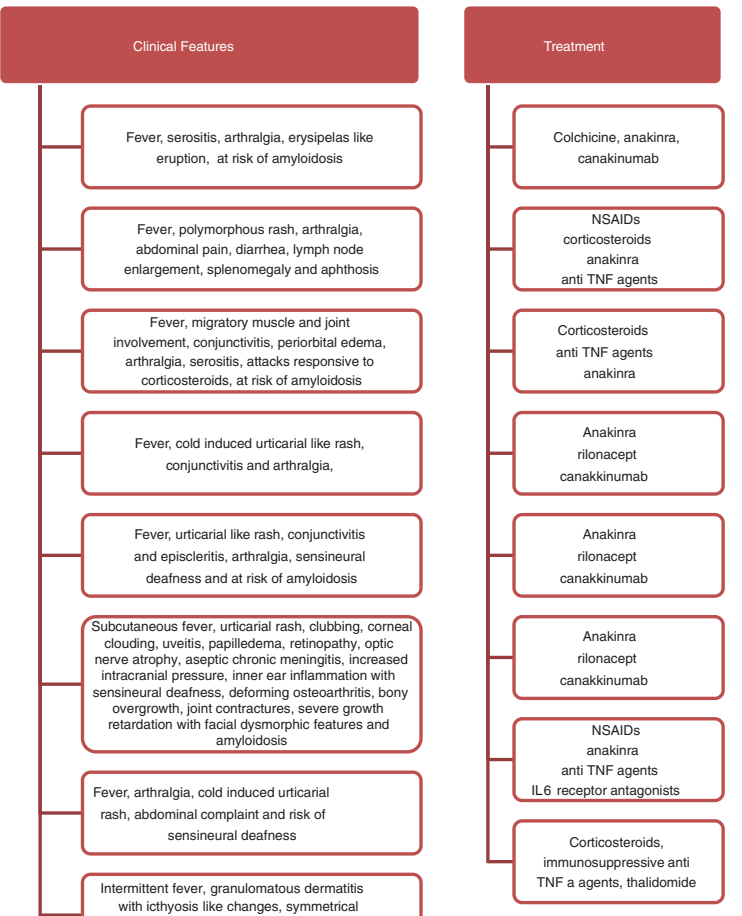

granulomatous polyarthritis, recurrent granulomatous panuveitis, risk of neuropathies
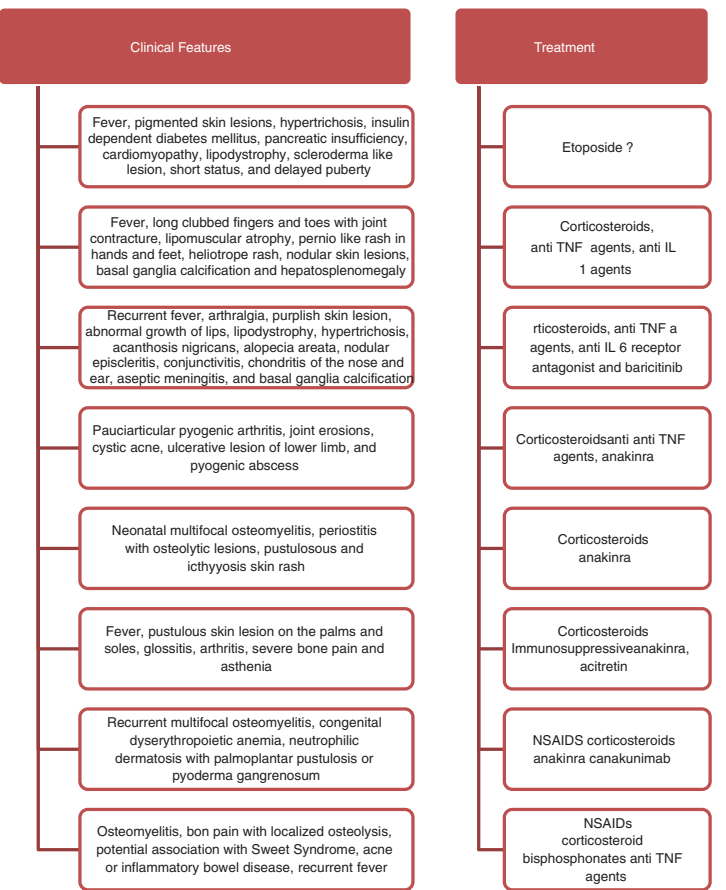

Mediterranean fever, MAJEEDs: Majeed syndrome, MKD: mevalonate kinase deficiency syndrome, MWS: MuckleWells syndrome, MLRP12-AD: NLRP12 associated autoinflammatory disease, NNS: Nakojo-Nishimura syndrome, NSAIDs: non-steroidal anti-inflammatory drugs, PAPA: pyogenic arthritis, poderma gangrenosum and acne syndrome, PHID: pigmentary hypertrichosis and non-autoimmune insulin dependent diabetes mellitus syndrome, TRAPS: tumor necrosis factor receptor associated periodic syndrome 
However, some occasionally AIS manifest as inflammation without fever and the inflammation can be persistent rather than episodic. The interval between attacks is variable, and the child remains completely well between febrile episodes. During attacks, laboratory tests are characterized by leukocytosis and elevation of acute phase reactants that normalize in the periods between fever episodes. A family history of these syndromes is often but not always obtained, including a history of unexplained deafness, renal failure, or amyloidosis. Initial workup for patients with AIS should be focused on ruling out serious conditions such as infection, malignancies, or immunodeficiency disorders. However, repeated attacks typically four to six attacks over an observation period of 9-12 months would require further genetic testing for AIS. Diagnosis of AIS can be challenging due to overlapping clinical features; however, AIS can be differentiated by age of onset, ethnicity, attack triggers, duration of attacks, disease-free intervals between attacks, clinical manifestations, and the response to therapy as described in (Table 24.3) [59, 60].

Table 24.3 Clues that help differentiate auto inflammatory syndromes

\begin{tabular}{|c|c|}
\hline \multicolumn{2}{|l|}{ Age of onset } \\
\hline At birth & NOMID, DIRA, FCAS \\
\hline Infancy and first year of life & HIDS, FCAS, NLRP12 \\
\hline Toddler & PFAPA \\
\hline Late childhood & PAPA \\
\hline $\begin{array}{l}\text { Most common of auto inflammatory syndromes to have onset in } \\
\text { adulthood }\end{array}$ & TRAPS, DITRA \\
\hline Variable (mostly in childhood) & All others \\
\hline \multicolumn{2}{|l|}{ Ethnicity and geography } \\
\hline Armenians, Turks, Italian, Sephardic Jaws & FMF \\
\hline Arabs & FMF, DITRA (Arab Tunisian) \\
\hline Dutch, French, German, Western Europe & HIDS, MWS, NLRP12 \\
\hline United States & FCAS \\
\hline Can occur in blacks (West Africa origin) & TRAPS \\
\hline Eastern Canada, Puerto Rico & DIRA \\
\hline Worldwide & All others \\
\hline \multicolumn{2}{|l|}{ Triggers } \\
\hline Vaccines & HIDS \\
\hline Cold exposure & FCAS, NLRP12 \\
\hline Stress, menses & FMF, TRAPS, MWS, PAPA, DITRA \\
\hline Minor trauma & PAPA, MWS, TRAPS, HIDS \\
\hline Exercise & FMF, TRAPS \\
\hline Pregnancy & DITRA \\
\hline Infections & All, especially DITRA \\
\hline \multicolumn{2}{|l|}{ Attack duration } \\
\hline$<24 \mathrm{~h}$ & FCAS, FMF \\
\hline $1-3 d$ & FMF, MWS, DITRA (fever) \\
\hline $3-7 d$ & HIDS, PFABA \\
\hline$>7 \mathrm{~d}$ & TRAPS, PAPA \\
\hline Almost always "in attack" & NOMID, DIRA \\
\hline \multicolumn{2}{|l|}{ Interval between attacks } \\
\hline $3-6 \mathrm{wk}$ & PFAPA, HIDS \\
\hline$>6 \mathrm{wk}$ & TRAPS \\
\hline Mostly unpredictable & All others \\
\hline Truly periodic & PFAPA, cyclic neutropenia \\
\hline \multicolumn{2}{|l|}{ Useful laboratory tests } \\
\hline Acute-phase reactants must be normal between attacks & PFAPA \\
\hline Urine mevalonic acid is attack & HIDS \\
\hline $\mathrm{IgD}>100 \mathrm{mg} / \mathrm{dL}$ & HIDS \\
\hline
\end{tabular}


Table 24.3 (continued)

\begin{tabular}{l|l}
\hline Age of onset & FMF, TRAPS, MWS, NOMID \\
\hline Proteinuria (amyloidosis) & \\
\hline Response to therapy & PFAPA \\
\hline Corticosteriod dramatic & TRAPS, FCAS, MWS, NOMID, PAPA ${ }^{\mathrm{a}}$ \\
\hline Corticosteriod partial & FMF, PFAPA (30\% effective) \\
\hline Colchicine & PFAPA (30\% effective) \\
\hline Cimetidine & TRAPS, FMF arthritis \\
\hline Etanercept & DIRA (anakinra), FCAS, MWS, NOMID, PFAPA \\
\hline Anti-IL-1 dramatic & TRAPS, FMF \\
\hline Anti-IL-1 mostly & HIDS, PAPA \\
\hline Anti-IL-1 partial & DRA, \\
\hline
\end{tabular}

Abbreviations: DIRA, deficiency of the IL-1 receptor antagonist; DITRA, deficiency of the IL-36 receptor antagonist (generalized pustular psoriasis); FCAS, familial cold auto inflammatory syndrome; FMF, familial Mediterranean fever; HIDS, hyperimmunoglobulinemia D syndrome; IL, interleukin; MWS, Muckle-Wells syndrome; NLRP, nucleotide oligomerization domain-like receptor family, pyrin domain; NOMID, neonatal-onset multisystem inflammatory disorder; PAPA, pyogenic sterile arthritis, pyoderma gangrenosum, acne syndrome; PFAPA, periodic fever, aphthous stomatitis, pharyngitis, adenitis; TRAPS, tumor necrosis factor receptor-associated periodic syndrome

Adapted from: Rigante D, Lapalco G, Vitale A et al. Untangling the Web of Systemic Inflammatory Diseases. Mediators

${ }^{\text {a }}$ For intra-articular steroids

Acknowledgments The authors would like to thank Dr. Waleed Hafiz for his assistance in the development of this chapter.

\section{References}

1. Hersh AO, von Scheven E, Yazdany J, et al. Differences in long-term disease activity and treatment of adult patients with childhood- and adultonset systemic lupus erythematosus. Arthritis Rheum. 2009;61:13-20.

2. Brunner HI, Gladman DD, Ibanez D, et al. Difference in disease features between childhood-onset and adult-onset systemic lupus erythematosus. Arthritis Rheum. 2008;58:556-62.

3. Tucker LB, Uribe AG, Fernandez M, et al. Adolescent onset of lupus results in more aggressive disease and worse outcomes: results of a nested matched casecontrol study within LUMINA, a multiethnic US cohort (LUMINA LVII). Lupus. 2008;17:314-22.

4. Tansley SL, McHugh NJ, Wedderburn LR, Bandeira M, Buratti S, Bartoli M, Gasparini C, Breda L, Pistorio A, et al. Relationship between damage accrual, disease flares and cumulative drug therapies in juvenile-onset systemic lupus erythematosus. Lupus. 2006;15:515-20.

5. Adult and juvenile dermatomyositis: are the distinct clinical features explained by our current understanding of serological subgroups and pathogenic mechanisms? Arthritis Research \& Therapy. 2013;15:211.

6. Mendez EP, Lipton R, Ramsey-Goldman R, et al. US incidence of juvenile dermatomyositis, 1995-1998: results from the National Institute of Arthritis and Musculoskeletal and Skin Diseases registry. Arthritis Rheum. 2003;49:300-5.
7. Pachman LM, Lipton R, Ramsey-Goldman R, et al. History of infection before the onset of juvenile dermatomyositis: results from the National Institute of Arthritis and Musculoskeletal and Skin Diseases research registry. Arthritis Rheum. 2005;53:166-72.

8. Rider L, Nistala K. The juvenile idiopathic inflammatory myopathies: pathogenesis, clinical and autoantibody phenotypes, and outcomes. Journal Internal Medicine. 2016;280:24-38.

9. Ravelli A, Trail L, Ferrari C, et al. Long-term outcome and prognostic factors of juvenile dermatomyositis: a multinational, multicenter study of 490 patients. Arthritis Care Res (Hoboken). 2010;62:63-72.

10. Sallum AM, Pivato FC, Doria-Filho U, et al. Risk factors associated with calcinosis of juvenile dermatomyositis. J Pediatr (Rio J). 2008;84:68-74.

11. Petty RE, Southwood TR, Manners P, et al. International league of associations for rheumatology. J Rheumatol. 2004;31:390-2.

12. Ravelli A, Martini A. Juvenile idiopathic arthritis. Lancet. 2007;369:767-78.

13. Al-Matar MJ, Petty RE, Tucker LB, Malleson PN, Schroeder ML, Cabral DA. The early pattern of joint involvement predicts disease progression in children with oligoarticular (pauciarticular) juvenile rheumatoid arthritis. Arthritis Rheum. 2002;46:2708-15.

14. Giancane G, Consolaro A, Lanni S, et al. Juvenile idiopathic Arthritis: diagnosis and treatment. Rheumatol Ther. 2016;3:187-207.

15. Ravelli A, Varnier GC, Oliveira S, et al. Antinuclear antibody-positive patients should be grouped as a separate category in the classification of juvenile idiopathic arthritis. Arthritis Rheum. 2011;63:267-75.

16. AmericanAcademy of PediatricsSection on Rheumatology and Section on Ophthalmology: Guidelines for ophthalmologic examinations in children with juvenile rheumatoid arthritis. Pediatrics. 1993;92:295-6. 
17. Petty RE, Cassidy JT. Textbook of pediatric rheumatology. Philadelphia: Saunders Elsevier; 2011.

18. van Dijkhuizen EH, Wulffraat NM. Early predictors of Prognosis in Juvenile Idiopathic Arthritis: Systamatic literature Review. Ann Rheum Dis. 2015;74:1996-200.

19. Cimaz R. Systemic onset juvenile idiopathic Arthritis. Autoimmun Rev. 2016;15:931-4.

20. Minoia F, Davi S, Horne A, Demirkaya E, Bovis F, $\mathrm{Li} \mathrm{C}$, et al. Clinical features, treatment, and outcome of macrophage activation syndrome complicating systemic juvenile idiopathic arthritis: a multinational, multicenter study of 362 patients. Arthritis Rheumatol. 2014;66:3160-9.

21. Ravelli A, Minoia F, Davì S, Paediatric Rheumatology International Trials Organisation.; Childhood Arthritis and Rheumatology Research Alliance.; Pediatric Rheumatology Collaborative Study Group, et al. Histiocyte Society 2016 Classification Criteria for Macrophage Activation Syndrome Complicating Systemic Juvenile Idiopathic Arthritis: A European League Against Rheumatism/American College of Rheumatology/Pediatric Rheumatology International Trials Organization Collaborative Initiative. Ann Rheum Dis. 2016;75:481-9.

22. Flat $\varnothing$ B, Lien G, Smerdel-Ramoya A, Vinje O. Juvenile psoriatic arthritis: longterm outcome and differentiation from other subtypes of juvenile idiopathic arthritis. J Rheumatol. 2009;36:642-50.

23. Stoll ML, Zurakowski D, Nigrovic LE, et al. Patients with juvenile psoriatic arthritis comprise two distinct populations. Arthritis Rheum. 2006;54:3564-72.

24. Zisman D, Gladman DD, Stoll ML, the CARRA Legacy Registry Investigators, et al. The Juvenile Psoriatic Arthritis Cohort in the CARRA Registry: Clinical Characteristics, Classification, and Outcomes. J Rheumatol. 2017. pii: jrheum.160717

25. Huemer C, Malleson PN, Cabral DA, et al. Patterns of joint involvement at onset differentiate oligoarticular juvenile psoriatic arthritis from pauciarticular juvenile rheumatoid arthritis. J Rheumatol. 2002;29:1531-5.

26. Saurenmann RK, Levin AV, Feldman BM, et al. Prevalence, risk factors, and outcome of uveitis in juvenile idiopathic arthritis: a long-term followup study. Arthritis Rheum. 2007;56:647-57.

27. Stoll ML, Bhore R, Dempsey-Robertson M, et al. Spondyloarthritis in a pediatric population: risk factors for sacroiliitis. J Rheumatol. 2010;37:2402-8.

28. Weiss PF, Klink AJ, Behrens EM, et al. Enthesitis in an inception cohort of enthesitis-related arthritis. Arthritis Care Res (Hoboken). 2011;63:1307-12.

29. Pagnini I, Savelli S, Matucci-Cerinic M, et al. Early predictors of juvenile sacroiliitis in enthesitis-related arthritis. J Rheumatol. 2010;37:2395-401.

30. Ramanathan A, Srinivasulu H, Colbert RA. Update on juvenile spondyloarthropathy. Rheum Dis Clin N Am. 2013;39:767-88.

31. Tsitsami E, Bozzola E, Magni-Manzoni S, et al. Positive family history of psoriasis does not aff ect the clinical expression and course of juvenile idiopathic arthritis patients with oligoarthritis. Arthritis Rheum. 2003;49:488-93.

32. Reiff A, Lovell DJ, Adelsberg JV, et al. Evaluation of the comparative efficacy and tolerability of rofecoxib and naproxen in children and adolescents with juvenile rheumatoid arthritis: a 12-week randomized controlled clinical trial with a 52-week open-label extension. J Rheumatol. 2006;33:985-95.

33. Ravelli A, Davì S, Bracciolini G, Pistorio A, et al. Italian Pediatric Rheumatology Study Group. Intraarticular corticosteroids versus intra-articular corticosteroids plus methotrexate in oligoarticular juvenile idiopathic arthritis: a multicentre, prospective, randomised, open-label trial. Lancet. 2017. pii: S0140-6736

34. Zulian F, Martini G, Gobber D, et al. Triamcinolone acetonide and hexacetonide intra-articular treatment of symmetrical joints in juvenile idiopathic arthritis: a double-blind trial. Rheumatology (Oxford). 2004;43:1288-91.

35. Tukova J, Chladek J, Nemcova D, Chladkova J, Dolezalova P. Methotrexate bioavailability after oral and subcutaneous administration in children with juvenile idiopathic arthritis. Clin Exp Rheumatol. 2009;27:1047-53.

36. Alsufyani K, Ortiz-Alvarez O, Cabral DA, Tucker LB, Petty RE, Malleson PN. The role of subcutaneous administration of methotrexate in children with juvenile idiopathic arthritis who have failed oral methotrexate. J Rheumatol. 2004;31:179-82.

37. Foell D, Wulffraat N, Wedderburn, et al. Methotrexate withdrawal at 6 vs 12 months in juvenile idiopathic arthritis in remission: a randomized clinical trial. JAMA. 2010;303:1266-73.

38. Silverman E, Mouy R, Spiegel L, et al. Leflunomide or methotrexate for juvenile rheumatoid arthritis. N Engl J Med. 2005;352:1655-66.

39. Giannini E, Ilowite N, Lovell et al. Long term safety and effectiveness of etanercept in children with selected categories of juvenile idiopathic arthritis. Arthritis Rheum 2009; 60; 2794-2804.

40. Lovell D, Ruperto N, Goodman S, et al. Adalimumab with or without methotrexate in juvenile rheumatoid Arthritis. Lovell et al NEJM. 2008;359:810-20.

41. Ruperto N, Lovell D, Quartier P, et al. Long-term safety and efficacy of abatacept in children with juvenile idiopathic arthritis. Arthritis Rheum. 2010;62:1792-802.

42. Quartier P, Allantaz F, Cimaz R, et al. A multicentre, randomized, double-blind, placebo-controlled trial with the interleukin-1 receptor antagonist anakinra in patients with systemic-onset juvenile idiopathic arthritis (ANAJIS trial). Ann Rheum Dis. 2011;70:747-54.

43. Brunner H, Ruperto N, Zuber Z, et al. Pediatric rheumatology international trials organization (PRINTO) and the pediatric rheumatology collaborative study group (PRCSG). Efficacy and safety of tocilizumab in patients with polyarticular-course juvenile idiopathic arthritis: results from a phase 3, randomized, double-blind withdrawal trial. Ann Rheum Dis. 2015;74:110-8. 
44. Wallace C, Giannini E, Spalding S, et al. Childhood Arthritis and Rheumatology Research Alliance trial of early aggressive therapy in polyarticular juvenile idiopathic arthritis. Arthritis Rheum. 2012;64:2012-21.

45. Tynjälä $P$, Vähäsalo $P$, Tarkiainen $M$, et al. Aggressive combination drug therapy in very early polyarticular juvenile idiopathic arthritis (ACUTE-JIA): a multicentre randomized open-label clinical trial. Ann Rheum Dis. 2011;70:1605-12.

46. Hissink Muller PC, Brinkman DM, Schonenberg $\mathrm{D}$, et al. A comparison of three treatment strategies in recent onset non-systemic Juvenile Idiopathic Arthritis: initial 3-months results of the BeSt for Kidsstudy. Pediatr Rheumatol Online J. 2017;15(1):11.

47. Ozen S, Ruperto N, Dillon MJ, et al. EULAR/ PReS endorsed consensus criteria for the classification of childhood vasculitides. Ann Rheum Dis. 2006;65:936-41.

48. Burns JC, Shike H, Gordon JB, et al. Sequelae of Kawasaki disease in adolescents and young adults. J Am Coll Cardiol. 1996;2:253-7.

49. Holman RC, Curns AT, Belay ED, Steiner CA, Effler PV, Yorita KL, et al. Kawasaki syndrome in Hawaii. Pediatr Infect Dis J. 2005;24:429-33.

50. Harnden A, Takahashi M, Burgner D. Kawasaki Disease. BMJ. 2009;338:b1514.

51. Newburger JW, Takahashi M, Gerber MA, et al. Diagnosis, treatment, and long term management of Kawasaki disease. Circulation. 2004;110:2747-71.
52. Dillon MJ, Eleftheriou D, Brogan PA. Medium-sizevessel vasculitis. Pediatr Nephrol. 2010;25:1641-52.

53. Brogan PA, Bose A, Burgner D, et al. Kawasaki disease: an evidence based approach to diagnosis, treatment, and proposals for future research. Arch Dis Child. 2002;86:286-90.

54. Kobayashi T, Saji T, Otani T, et al. Efficacy of immunoglobulin plus prednisolone for prevention of coronary artery abnormalities in severe Kawasaki disease (RAISE study): a randomised, open-label, blindedendpoints trial. Lancet. 2012;379:1613-20.

55. Kobayashi T, Inoue Y, Takeuchi K, et al. Prediction of intravenous immunoglobulin unresponsiveness in patients with Kawasaki disease. Circulation. 2006;113:2606-12.

56. Wardle AJ, Connolly GM, Seager MJ, Tulloh RM. Corticosteroids for the treatment of Kawasaki disease in children. Cochrane Database Syst Rev. 2017;1:CD011188.

57. Eleftheriou D, Levin M, Shingadia D, Tulloh R, Klein NJ, Brogan PA. Management of Kawasaki Disease. Arch Dis Child. 2014;99:74-83.

58. Federici S, Gatoron M. A practical approach to the diagnosis of autoinflammatory disease in childhood. Best Pract Res Clin Rheumatol. 2014;28:263-76.

59. Hashkes P, Toker O. Autoinflammatory syndromes. Pediatr Clin N Am. 2012;59:447-70.

60. Rigante D, Lapalco G, Vitale A, et al. Untangling the Web of Systemic Inflammatory Diseases. Mediators of Inflammation. 2014;948154:15.

Open Access This chapter is licensed under the terms of the Creative Commons Attribution 4.0 International License (http://creativecommons.org/licenses/by/4.0/), which permits use, sharing, adaptation, distribution and reproduction in any medium or format, as long as you give appropriate credit to the original author(s) and the source, provide a link to the Creative Commons license and indicate if changes were made.

The images or other third party material in this chapter are included in the chapter's Creative Commons license, unless indicated otherwise in a credit line to the material. If material is not included in the chapter's Creative Commons license and your intended use is not permitted by statutory regulation or exceeds the permitted use, you will need to obtain permission directly from the copyright holder. 